\title{
Analysis of pre-earthquake ionospheric anomalies before the global $M=7.0+$ earthquakes in 2010
}

\author{
Y. B. Yao, P. Chen, S. Zhang, J. J. Chen, F. Yan, and W. F. Peng \\ School of Geodesy and Geomatics, Wuhan University, Wuhan, China \\ Correspondence to: Y. B. Yao (ybyao@whu.edu.cn)
}

Received: 5 October 2011 - Revised: 19 January 2012 - Accepted: 19 January 2012 - Published: 6 March 2012

\begin{abstract}
The pre-earthquake ionospheric anomalies that occurred before the global $M=7.0+$ earthquakes in 2010 are investigated using the total electron content (TEC) from the global ionosphere map (GIM). We analyze the possible causes of the ionospheric anomalies based on the space environment and magnetic field status. Results show that some anomalies are related to the earthquakes. By analyzing the time of occurrence, duration, and spatial distribution of these ionospheric anomalies, a number of new conclusions are drawn, as follows: earthquake-related ionospheric anomalies are not bound to appear; both positive and negative anomalies are likely to occur; and the earthquake-related ionospheric anomalies discussed in the current study occurred 0-2 days before the associated earthquakes and in the afternoon to sunset (i.e. between 12:00 and 20:00 local time). Pre-earthquake ionospheric anomalies occur mainly in areas near the epicenter. However, the maximum affected area in the ionosphere does not coincide with the vertical projection of the epicenter of the subsequent earthquake. The directions deviating from the epicenters do not follow a fixed rule. The corresponding ionospheric effects can also be observed in the magnetically conjugated region. However, the probability of the anomalies appearance and extent of the anomalies in the magnetically conjugated region are smaller than the anomalies near the epicenter. Deep-focus earthquakes may also exhibit very significant pre-earthquake ionospheric anomalies.
\end{abstract}

\section{Introduction}

Recently, pre-earthquake ionospheric anomalies have drawn intensive attention (Astafyeva and Heki, 2011; Calais and Minster, 1995; Chavez et al., 2011; Dautermann et al., 2007; Hasbi et al., 2011; Kim and Hegai, 1999; Oyama et al., 2008). Earthquake ionospheric effects are becoming a hotspot of earthquake precursor information exploration.
By studying the data recorded by four ionosonde stations in China and Japan, Zhao et al. (2008) found that the critical frequencies of the $F_{2}$ layer $\left(\mathrm{foF}_{2}\right)$ of these ionosonde stations exhibited significant increases within three days before the 12 May 2008 Wenchuan earthquake, and the increases in two ionosonde stations in China were more evident. Liu et al. (2009) found obvious positive and negative ionospheric anomalies within 3 and 6 days before the 12 May 2008 Wenchuan earthquake, respectively. The most affected area in the ionosphere was located on the equator side of the epicenter. Liu et al. (2006) analyzed the spatial and temporal distribution of the electron density in the ionosphere before the 26 September 2004 Sumatra earthquake and found an obvious negative anomaly. Sharma et al. (2010) analyzed the unusual variations in the ionospheric total electron content (TEC) and foF $_{2}$ within a few days before the main shock of the three major earthquakes $(M>6)$ in China. They found that the pre-earthquake ionospheric anomaly occurred between 11:00 LT and 17:00 LT and was a local phenomenon. Some of the stations appeared anomalous, whereas the others did not. Yao et al. (2012) investigated pre-earthquake ionospheric anomalies during the 2011 $M_{\mathrm{w}}=9.0$ Japan earthquake period, using data from GPS and ionosonde stations near the epicenter. They inverted the spatial and temporal distribution of electron density in the ionosphere, and attested an ionospheric precursor of the 11 March earthquake in Japan. Le et al. (2011) statistically evaluated the appearance of pre-earthquake ionospheric anomaly for 736 earthquakes of $M \geq 6.0$ that occurred across the globe between 2002 and 2010. They found that the occurrence rate of the pre-earthquake ionospheric anomalies had a relationship with the magnitude, the depth, and the proximity of the days prior to the occurrence of the earthquakes. A higher occurrence rate of anomalies is exhibited by earthquakes with larger magnitudes and lower depths and in the days closer to the occurrence of the earthquakes. He et al. (2011) used 
Table 1. Information on the seven selected earthquakes (http://earthquake.usgs.gov).

\begin{tabular}{llrrrr}
\hline $\begin{array}{l}\text { Epicenter } \\
\text { Region }\end{array}$ & $\begin{array}{l}\text { Occurrence } \\
\text { Time (UT) }\end{array}$ & $\begin{array}{r}\text { LT-UT } \\
(\mathrm{h})\end{array}$ & $\begin{array}{r}\text { Epicenter } \\
\text { Coordinates }\end{array}$ & $\begin{array}{r}\text { Magnitude } \\
\begin{array}{r}\text { Depth } \\
(\mathrm{km})\end{array}\end{array}$ \\
\hline Haiti region & 12 Jan 2010, 21:53:10 & -5 & $18.443^{\circ} \mathrm{N}, 72.571^{\circ} \mathrm{W}$ & $M=7.0$ & 13 \\
Offshore Bio-Bio, Chile & 27 Feb 2010, 06:34:14 & -5 & $35.909^{\circ} \mathrm{S}, 72.733^{\circ} \mathrm{W}$ & $M=8.8$ & 35 \\
Baja California, Mexico & 04 Apr 2010, 22:40:42 & -8 & $32.259^{\circ} \mathrm{N}, 115.287^{\circ} \mathrm{W}$ & $M=7.2$ & 10 \\
Ecuador & 12 Aug 2010, 11:54:15 & -5 & $1.260^{\circ} \mathrm{S}, 77.312^{\circ} \mathrm{W}$ & $M=7.1$ & 211 \\
South Island of New Zealand & 03 Sep 2010, 16:35:46 & +11 & $43.530^{\circ} \mathrm{S}, 172.120^{\circ} \mathrm{E}$ & $M=7.0$ & 5 \\
Papua, Indonesia & 29 Sep 2010, 17:11:24 & +9 & $4.920^{\circ} \mathrm{S}, 133.783^{\circ} \mathrm{E}$ & $M=7.2$ & 12.3 \\
Bonin Islands, Japan & 21 Dec 2010,17:19:40 & +10 & $26.892^{\circ} \mathrm{N}, 143.726^{\circ} \mathrm{E}$ & $M=7.4$ & 14 \\
\hline
\end{tabular}

the electron density data recorded by the DEMETER satellite to perform a statistical analysis of ionospheric anomalies before $M=5.0+$ earthquakes during 2006-2009. They also found that the intensity of the anomalies was enhanced when the magnitude increased, and was reduced when the depth increased.

Previous studies showed that the ionospheric electron density or TEC over a forthcoming epicenter region tends to significantly change in the afternoon and/or in the evening within 1-6 days before earthquake occurrence. The anomaly duration is approximately $4-12 \mathrm{~h}$. The location of the anomaly peak does not coincide with the vertical projection of the epicenter, but is located at the equator side of the epicenter. A corresponding ionospheric effect is also observed in the magnetically conjugated region (Pulinets et al., 2003; Pulinets and Boyarchuk, 2004; Pulinets, 2007).

The current paper presents a study of the pre-earthquake ionospheric anomalies before the global $M=7.0+$ earthquakes in 2010. By analyzing the occurrence moment, duration, and spatial distribution of these ionospheric anomalies, some new conclusions are drawn.

\section{Data and methods of anomaly analysis}

We selected seven $M=7.0+$ earthquakes, which occurred in different regions of the world in 2010, as research subjects to exclude the interference of other earthquakes and analyze the ionospheric anomalies prior to the earthquakes, ensuring that no other strong earthquakes within 15 days before each earthquake occurred. The information and distribution of the seven selected earthquakes are shown in Table 1 and Fig. 1.

Global ionosphere maps (GIM) with a $2 \mathrm{~h}$ time resolution provided by International GNSS Service (IGS) were used to analyze the pre-earthquake ionospheric anomalies. Resolutions in the latitudinal and longitudinal directions are $2.5^{\circ}$ and $5^{\circ}$, respectively. We used the TEC of the grid points around the epicenter to interpolate the epicenter TEC series. To detect abnormal signals of the GPS TEC variations, a "sliding window" based method was performed. At each time point on any day, we computed the median $(\mu)$ and standard deviation $\sigma$ for the GPS TEC of 1-30 days before the day. The ionospheric TEC was considered to follow a

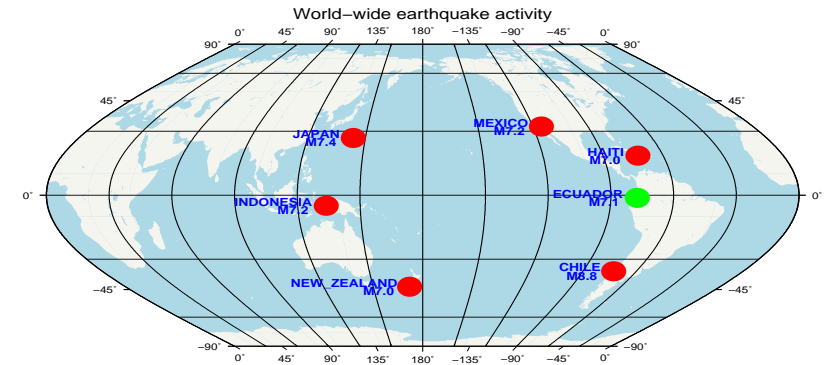

Fig. 1. Global distribution of the seven selected earthquakes.

normal distribution with median $\mu$ and standard deviation $\sigma$. We have done a statistical analysis for a large amount of TEC, and referred to other scholars' literature. We think it is suitable to choose $1.5 \sigma$ (confidence level $86.64 \%$ ) as the boundary of anomaly determination (i.e. the variation in the TEC should be less than $\mu \pm 1.5 \sigma$ ). If the TEC value was larger than $\mu+1.5 \sigma$, it was defined as a positive anomaly; and if the TEC value was smaller than $\mu-1.5 \sigma$, it was defined as a negative anomaly. Each day (0-14 days) before an earthquake was checked by the "sliding window" method described above.

We statistically analyzed the times of anomalies of each grid point during the anomalous period to determine the spatial distribution of the ionospheric anomalies. Because the higher repeat times indicate longer anomalous duration, one can get the spatial distribution of the ionospheric anomalies by analyzing the global distribution of the grid points with different anomalies times (Liu et al., 2011).

The ionosphere can be affected by many factors, among which solar and geomagnetic field activities are the most important. When discussing the relationship between ionospheric anomaly and earthquake, the solar terrestrial environment must be taken into account to exclude anomalies that may have been caused by solar or magnetic field activities (Pulinets et al., 2003; Pulinets, 2007). In the present study, the Dst, $F_{10.7}$, and $K_{p}$ indices were used to describe the solar and geomagnetic field activities before and after the earthquakes. 


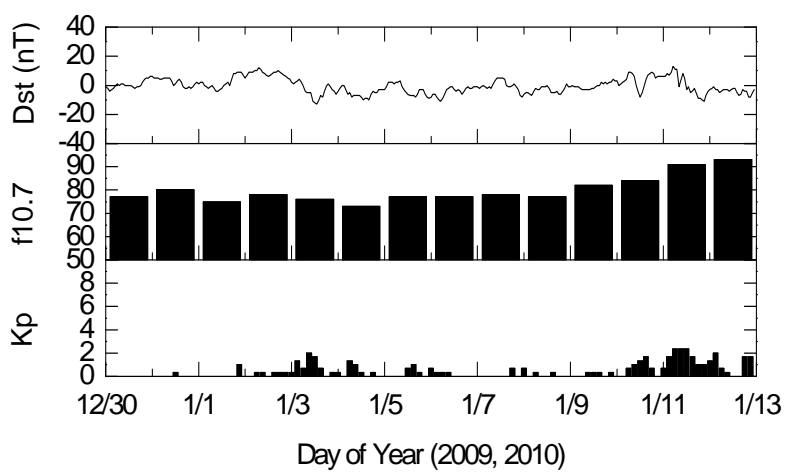

Fig. 2. Dst, $F_{10.7}$, and $K_{p}$ indices during 30 December 2009 to 12 January 2010.

\section{Pre-earthquake ionospheric anomaly analysis}

\subsection{Haiti $M=7.0$ earthquake on 12 January 2010}

Figure 2 shows the Dst, $F_{10.7}$, and $K_{p}$ indices during 30 December 2009 to 12 January 2010. The variations in the Dst index were within $\pm 13 \mathrm{nT}$, those of the $K_{p}$ index were below 2 , and that of the maximum $F_{10.7}$ index was 93 , indicating that the space environment and the geomagnetic field were very quiet within 14 days before the earthquake. Figure 3 shows the TEC time series of the epicenter within 14 days before the earthquake, revealing that obvious positive anomalies occurred one day before the earthquake, continued for over $24 \mathrm{~h}$, and then reached a maximum at 17:00 LT, $11 \mathrm{Jan}-$ uary 2010. However, the space environment and the geomagnetic field were very quiet during that day. Therefore, preliminary confirmation can be made that the ionospheric anomaly observed on 11-12 January 2010 was related to the impending earthquake.

We collated a statistics of the repeated times of the abnormal points in the GIM grid file during 11-12 January 2010 to further describe the global distribution of the ionospheric anomaly in this day. Figure 4 shows the distribution of the grid points, which were repeated evenly. The figure reveals that the grid points repeated less than four times were globally distributed, while others were focused over the epicenter gradually. Those repeated more than six times were mainly focused over the epicenter, its magnetic equatorial conjugate points, and the northern hemisphere high-latitude areas. The points repeated more than ten times were mainly focused over the epicenter and its magnetic equatorial conjugate points. The points repeated more than 14 times were almost focused northwest of the epicenter, which ranged from $15^{\circ} \mathrm{N} \sim 35^{\circ} \mathrm{N},-120^{\circ} \mathrm{E} \sim-60^{\circ} \mathrm{E}$. Some grid points near the epicenter were repeated 16 times, which means the anomaly duration exceed $32 \mathrm{~h}$. Considering the rather long anomaly duration and the distribution of the grid points near the epicenter, we can further confirm that the ionospheric anomaly observed on 11-12 January 2010 was related to the impending earthquake.

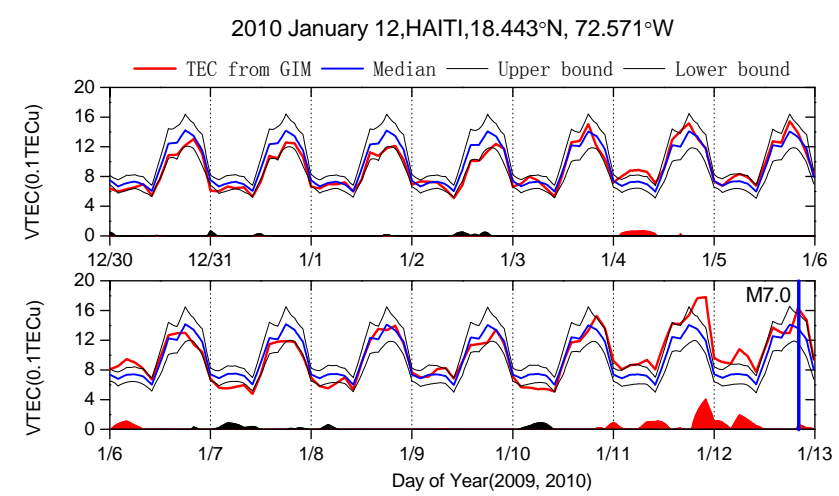

Fig. 3. VTEC time series above the Haiti epicenter from 30 December 2009 to 12 January 2010. The red, blue, and two black curves denote the observed TEC, associated median, and upper/lower bound (UB/LB), respectively. The red and black shade areas denote difference of O-UB and LB-O, respectively, where $\mathrm{O}$ is observed TEC.

\subsection{Chile $M=8.8$ earthquake on 27 February 2010}

Figure 5 shows the Dst, $F_{10.7}$, and $K_{p}$ indices during 14 27 February 2010. The Dst index $<-40 \mathrm{nT}$ on $15-16$ February 2010, and the minimum was $-58 \mathrm{nT}$. Geomagnetic storms occurred in those days and lasted until 18-19 February 2010. However, the geomagnetic field was very quiet in the rest of the days. Solar activity was very quiet during this period $\left(F_{10.7}<90\right)$.

Figure 6 shows the epicenter TEC time series, which reveals that TEC clearly increased on 15-16 February and the anomaly continued for a long time. Anomalies also occurred on 18 and 20 February. By cross-referencing the weather condition during those anomalous days with the strength of the magnetic field activities, the ionospheric anomaly on 1516 February was found to be caused by a geomagnetic disturbance. The anomaly on 18 February lasted for a very short time. On 20 February, the geomagnetic field and solar activity were very quiet; thus, the ionospheric anomaly on that day was not caused by spatial environments disturbance. However, 20 February was seven days prior to the earthquake; thus, we could not confirm the relationship between the ionospheric anomaly and the earthquake. And no atmospheric anomalies occurred on 21-26 February.

The Chile earthquake reached a very high magnitude of 8.8 on 27 February. However, no obvious ionospheric anomaly was detected within seven days before the earthquake. Whether the ionospheric anomaly is related to other factors, such as the earthquake focal mechanism, still needs further study.

\subsection{Mexico $M=7.2$ earthquake on 4 April 2010}

Figure 7 shows the 14-day Dst, $F_{10.7}$, and $K_{p}$ indices during 22 March 2010 to 4 April 2010. The geomagnetic field was very quiet within 14 days before the earthquake. 

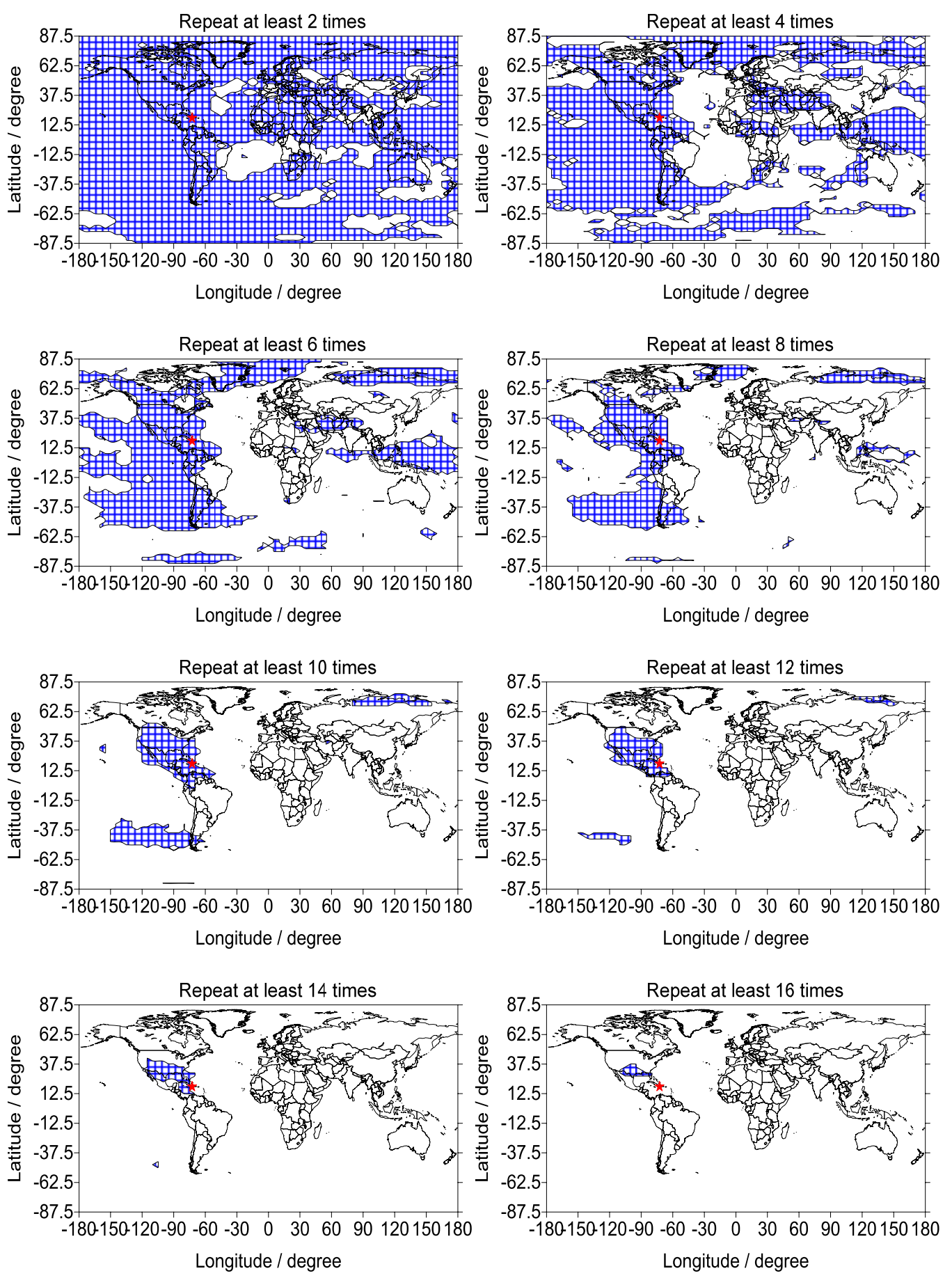

Fig. 4. Locations of the 30-day extreme enhancement that repeatedly appeared at various time points on 11-12 January 2010. The number of repeat time points is noted on top of each panel. The red star symbol denotes the epicenter.

Figure 8 shows the epicenter TEC time series, which reveals that several positive anomalies appeared on 2428 March 2010. The geomagnetic field was very quiet during those days. Therefore, the spatial environment disturbance did not cause the ionospheric anomalies. However, these dates were more than seven days prior to the earthquake on
4 April; thus, we could not confirm the relationship between the ionospheric anomaly and the earthquake. Further study should be conducted to ascertain the cause of the anomalies. No obvious ionospheric anomaly was detected within seven days before the earthquake. 


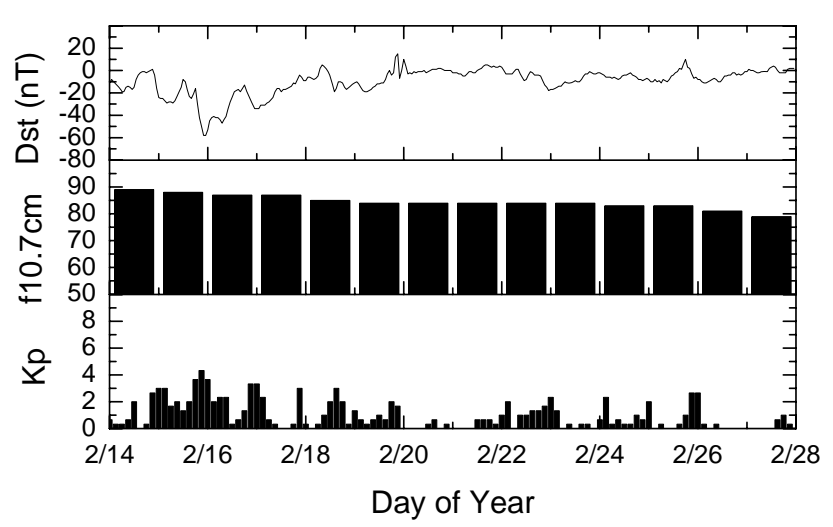

Fig. 5. Dst, $F_{10.7}$, and $K_{p}$ indices during 14-27 February 2010.

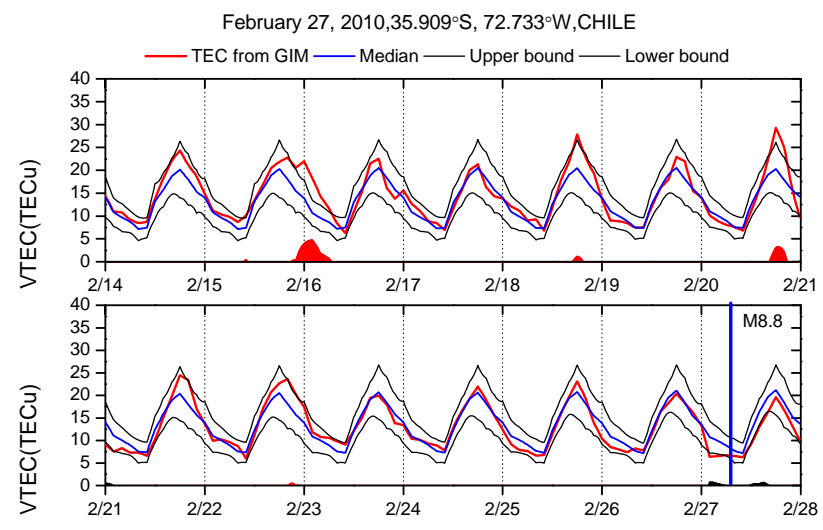

Fig. 6. VTEC time series above the Chile epicenter during 14 February 2010 to 27 February 2010. Symbols in this figure are the same as those in Fig. 3.

\subsection{Ecuador $M=7.1$ earthquake on 12 August 2010}

Figure 9 shows the 14-day Dst, $F_{10.7}$, and $K_{p}$ indices during 30 July 2010 to 12 August 2010. The figure reveals that geomagnetic storms occurred on 3-5 August, which continued until 8 August. The Dst index reached $-65 \mathrm{nT}$ at 04:00 UT on 4 August. The spatial environment and the geomagnetic field were relatively quiet. Figure 10 shows the 14-day TEC observations of the epicenter and the associated median and upper and lower bounds before the earthquake. Positive ionospheric anomalies occurred on 4-8 August and 11 August. Based on the analysis of the 14-day spatial environment and geomagnetic field, one can learn the ionospheric positive anomalies occurring on 4-8 August were probably caused by geomagnetic field disturbance. However, an obvious ionospheric positive anomaly occurred one day before the earthquake, from 04:30 LT to 21:30 LT, and lasted for $12 \mathrm{~h}$. The maximal anomalous value was above $29.8 \%$ of the median. However, the space environment on that day was quiet $\left(K_{p}<4\right.$, Dst $\left.>-20 \mathrm{nT}\right)$. Therefore, the ionospheric positive anomaly was probably related to the earthquake on 12 August.

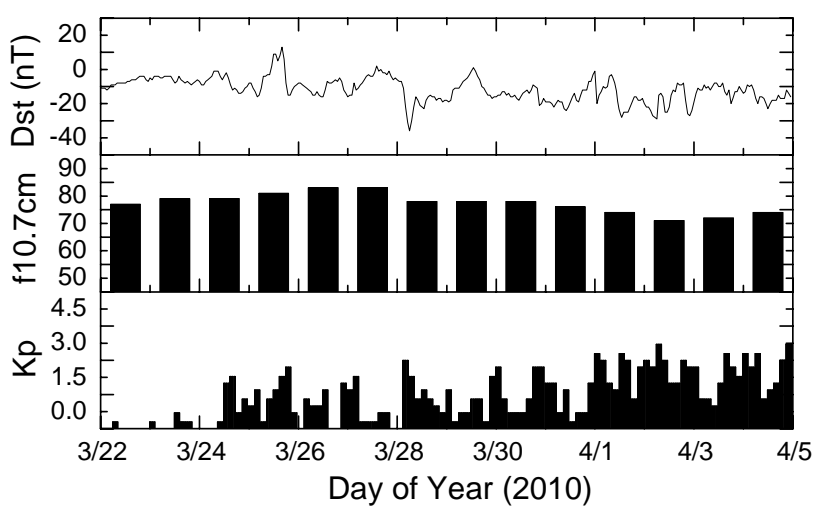

Fig. 7. Dst, $F_{10.7}$, and $K_{p}$ indices during 22 March 2010 to 4 April 2010.

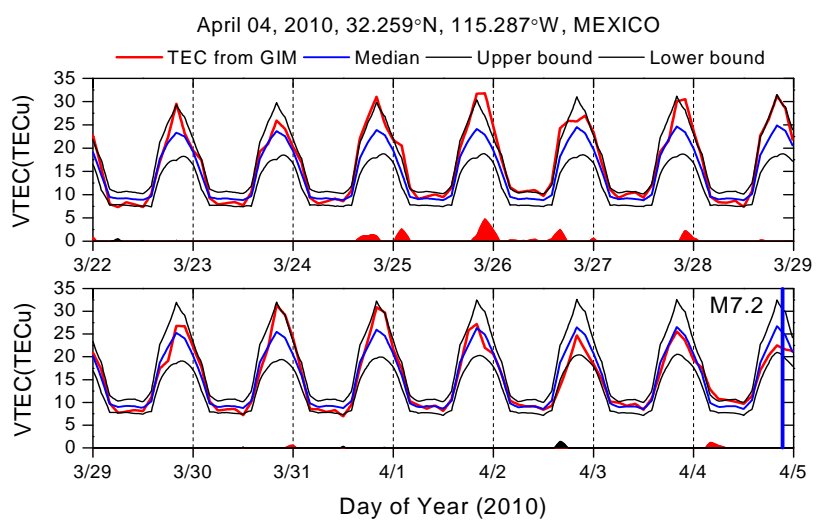

Fig. 8. VTEC time series above the Mexico epicenter during 22 March 2010 to 4 April 2010. Symbols in this figure are the same as those in Fig. 3.

The number of times of each grid point occurring anomalies from 04:00 LT to 18:00 LT on 11 August 2010 was counted (Fig. 11). The grid points with anomalies were mainly distributed in the Southern Hemisphere. The grid points repeated less than 3 times had wider distributions, those repeated 5-6 times were mainly focused over the west of the epicenter, and those repeated 6 times were distributed in areas with $>50^{\circ}$ longitude and $>20^{\circ}$ latitude. The distribution of the ionospheric anomalies confirms the relationship between the anomaly and the earthquake.

The hypocenter depth of this earthquake was $211 \mathrm{~km}$, and obvious pre-earthquake ionospheric anomalies occurred. Therefore, the hypocenter depth cannot be the main factor determining whether pre-earthquake ionospheric anomaly occurs. 


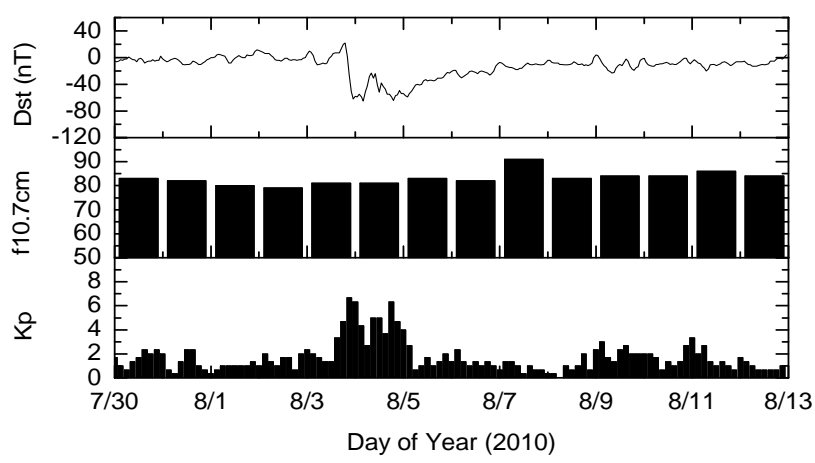

Fig. 9. Dst, $F_{10.7}$, and $K_{p}$ indices during 30 July 2010 to $12 \mathrm{Au}-$ gust 2010 .

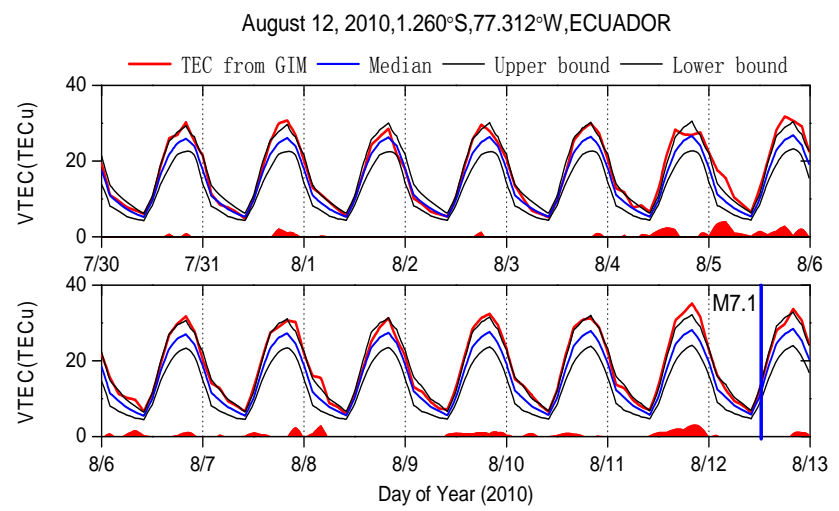

Fig. 10. VTEC time series above the Ecuador epicenter during 30 July 2010 to 12 August 2010. Symbols in this figure are the same as those in Fig. 3.

\subsection{New Zealand $M=7.0$ earthquake on 3 September 2010}

Figure 12 shows the 14-day Dst, $F_{10.7}$, and $K_{p}$ indices during 21 August 2009 to 3 September 2009. A geomagnetic disturbance occurred on 23-24 August 2010. The Dst index decreased from $49 \mathrm{nT}$ at 22:00 UT, 23 August to $-33 \mathrm{nT}$ at 12:00 UT, 24 August. On the other days, the Dst index remained unchanged.

Figure 13 shows the epicenter TEC time series, which indicates that ionospheric positive anomalies occurred on 2325 August and 2 September. The ionospheric anomalies on 23-25 August were caused by magnetic disturbances. Anomalies on 2 September continued from 16:30 LT to 23:30 LT. The maximal anomalous value was above $43.8 \%$ of the median, but the spatial environment and geomagnetic field were very quiet on that day. Therefore, the anomaly is probably related to the earthquake that occurred on 3 September. The number of times of each grid point occurring anomalies from 16:00 LT, 2 September 2010 to 00:00 LT, 3 September 2010 was counted to confirm the relationship between the ionospheric anomaly on that day and the earthquake. The result is shown in Fig. 14. The grid points repeated only once were globally distributed, and those repeated more than once were focused near the epicenter. The grid points repeated four times all focused over the equator side of the epicenter, with length ratio of approximately $3: 1$ on longitudinal and latitudinal directions. These findings strongly prove that the ionospheric anomaly is related to the earthquake.

\subsection{Indonesia $M=7.2$ earthquake on 29 September 2010}

Figure 15 shows the Dst, $F_{10.7}$, and $K_{p}$ indices during 16 29 September 2010. The figure shows that the Dst index decreased $43 \mathrm{nT}$ from 13:00 UT, 16 September to 8:00 UT, 17 September, and further declined 50 nT from 15:00 UT, 24 September to 9:00 UT, 17 September. The geomagnetic field was examined. The spatial environment and the geomagnetic field were calm during the rest of the days.

Figure 16 shows the TEC time series of the earthquake. The TEC on 16, 17-18, 20-25, and 28 September significantly increased. The causes of the ionospheric anomalies were analyzed via cross-referencing with the geomagnetic field and the spatial weather environment. Figure 15 shows that ionospheric disturbances occurred on 16-17 September. The effect of the ionospheric disturbances lasted until 23-24 September. The same event occurred on 27 September. Therefore, the ionospheric anomalies occurred because of the ionospheric disturbances. Ionospheric anomalies occurred from 08:15 LT to 16:45 LT on 28 September, with the maximal anomalous value surpassing the median by $50 \%$. $K_{p}$ index increased on that day, but Dst index was relatively quiet. The ionospheric anomalies were probably caused by the earthquake, which occurred in the next day.

Repeated times of the abnormal points on 28 September 2010 was counted to further determine the relationship between the ionospheric anomalies and the earthquake that occurred in the next day. Figure 17 shows that the grid points repeated once were mostly focused over the east of the epicenter and widely spread, whereas the grid points repeated 2 to 4 times were mostly focused over the east of the epicenter and near the conjugate point.

\subsection{Japan $M=7.4$ earthquake on 21 December 2010}

Figure 8 shows the 14-day Dst, $F_{10.7}$, and $K_{p}$ indices during 8-21 December 2010. The Dst index significantly changed on 20 December and decreased 46 nT from 03:00 UT to 11:00 UT. And geomagnetic field disturbances were detected on this day. While the $F_{10.7}$ index for the rest of the days was no more than 90, and the $K_{p}$ index was less than 4, the spatial environment and the geomagnetic activity were relatively quiet during these days. 

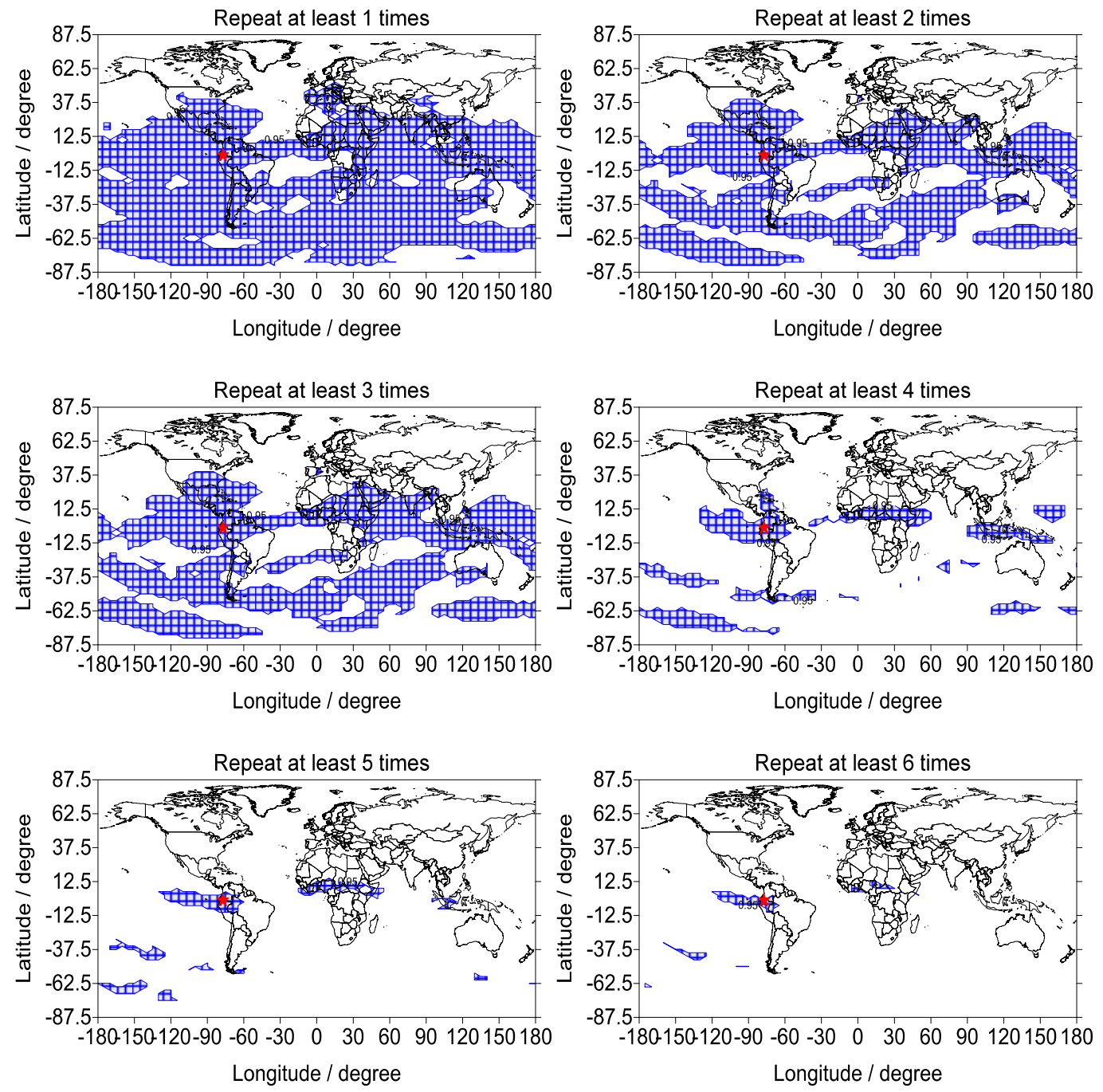

Fig. 11. Locations of the 30-day extreme enhancement that repeatedly appeared at various time points on 12 August 2010.

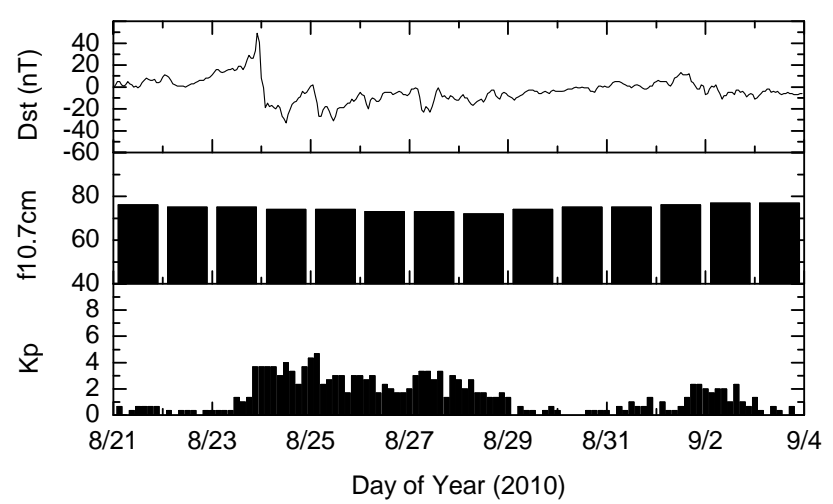

Fig. 12. Dst, $F_{10.7}$, and $K_{p}$ indices during 21 August 2010 to 3 September 2010.
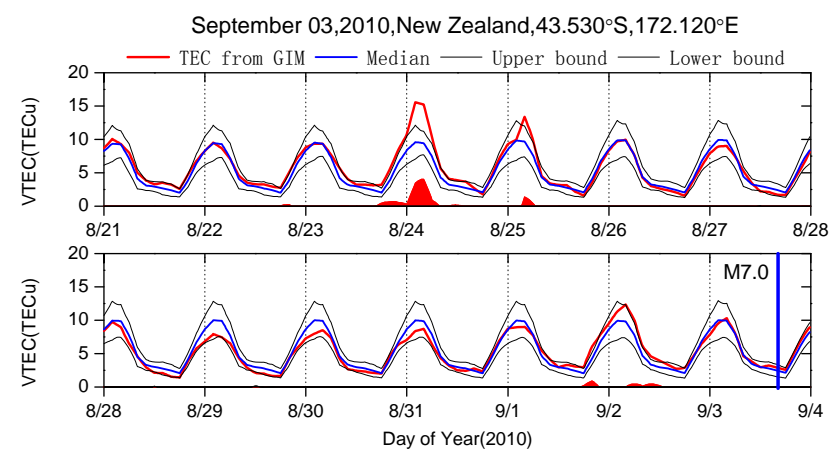

Fig. 13. VTEC time series above the New Zealand epicenter during 21 August 2010 to 3 September 2010. Symbols in this figure are the same as those in Fig. 3. 

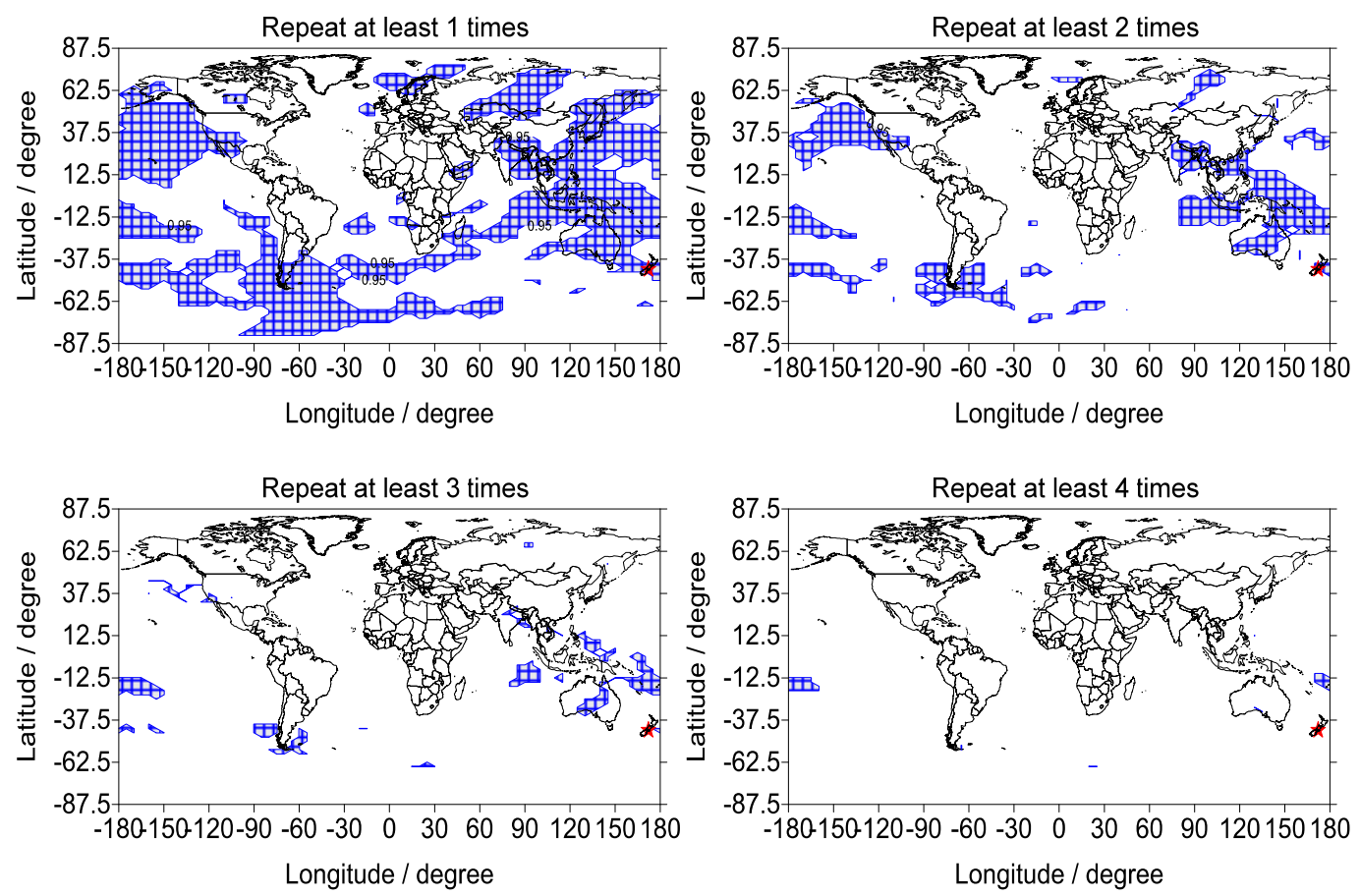

Fig. 14. Locations of the 30-day extreme enhancement that repeatedly appeared at various time points on 2 September 2010.

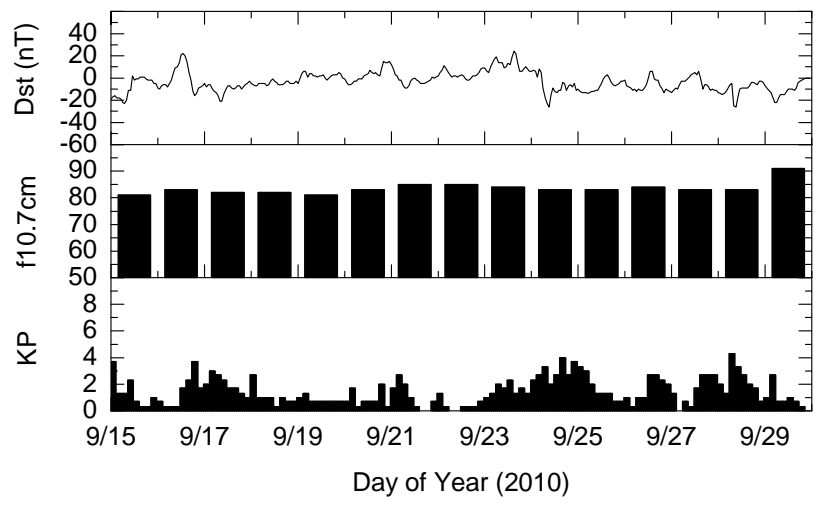

Fig. 15. Dst, $F_{10.7}$, and $K_{p}$ indices during 15-29 September 2011.

Figure 19 shows the TEC time series of the earthquake. Negative TEC anomalies were shown on 19 December, which lasted from 12:45 LT to 21:00 LT, with the maximum anomalous value exceeding the median by $30 \%$. The space environment was quiete on that day. Therefore, we considered that the anomaly was related to the earthquake that occurred two days later.

The frequency of the anomalies in every grid from 12:00 LT to 20:00 LT on 19 December 2010 was determined to confirm the association between the ionospheric anomalies and the earthquake that occurred two days later. The result is shown in Fig. 20. The grid points that repeated once

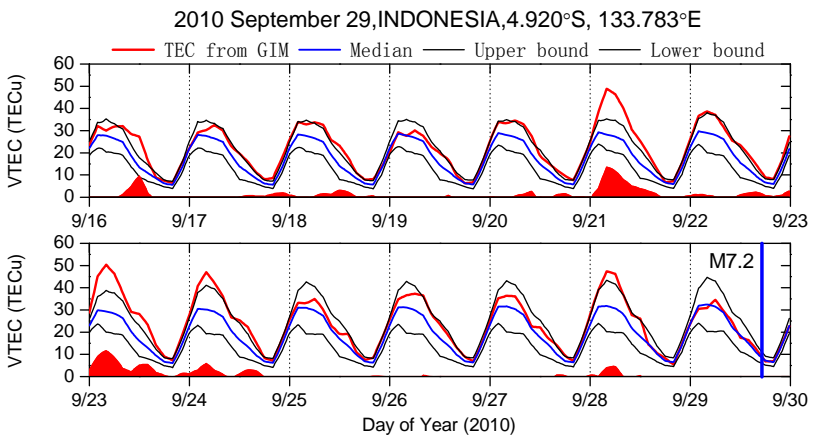

Fig. 16. VTEC time series above the Indonesian epicenter during 16 September 2010 to 29 September 2010. Symbols in this figure are the same as those in Fig. 3.

were more widely distributed, with the majority concentrated (over the) north of the equator in the Eastern Hemisphere. The grid points repeated 2 to 3 times were mainly concentrated over eastern Asia, and those repeated several times were mainly concentrated in the vicinity of the epicenter. The grid points repeated 4 to 5 times were concentrated over the west side of the equator of the epicenter. The distribution of near the epicenter of abnormal grid points further confirm the correlation between the ionospheric anomalies and the earthquake that occurred two days later. 

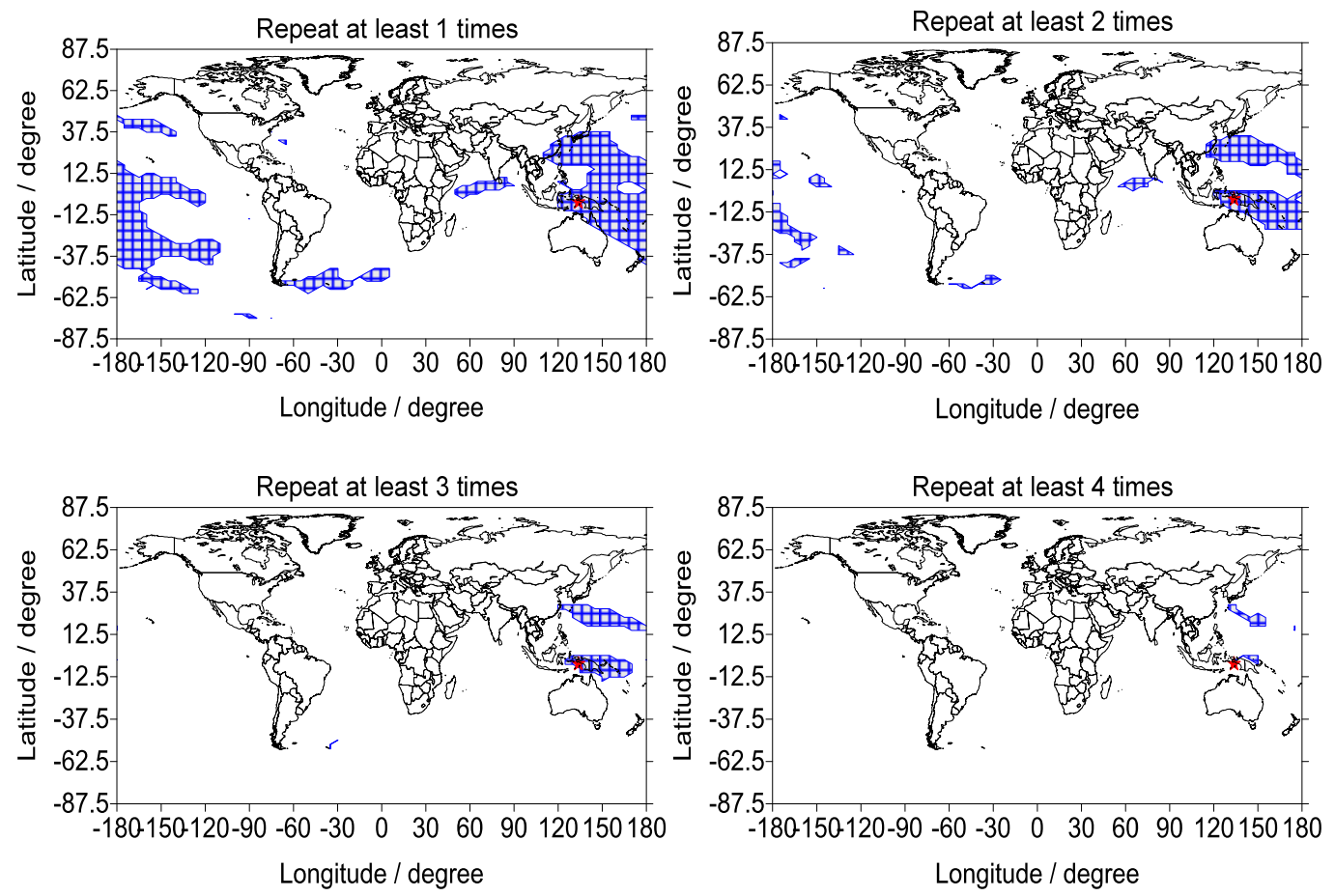

Fig. 17. Locations of the 30-day extreme enhancement that repeatedly appeared at various time points on 28 September 2010.

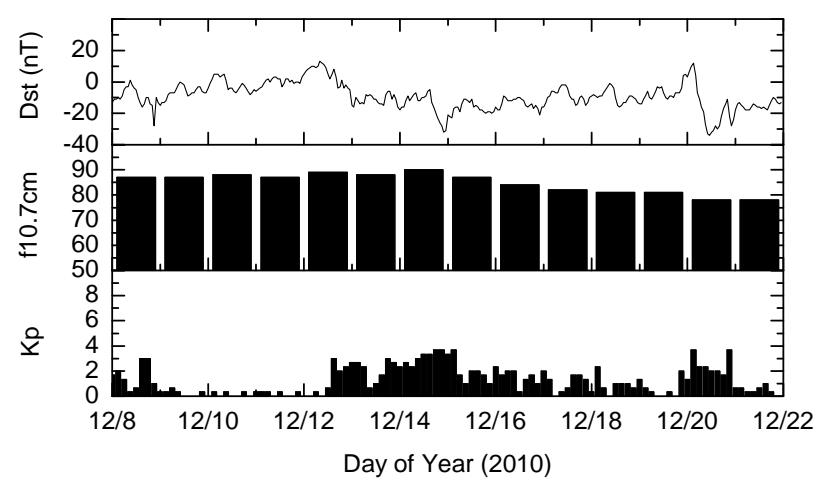

Fig. 18. Dst, $F_{10.7}$, and $K_{p}$ indices during 8-21 December 2010.

\section{Conclusions}

The current paper presents a study on the pre-earthquake ionospheric anomalies that occurred prior to the global $M=$ $7.0+$ earthquakes in 2010. Using GIM data provided by IGS, we applied a 30-day sliding window method to detect the ionospheric anomalies within 0-14 days before the earthquakes with a tolerance of $1.5 \sigma$. Excluding the anomalies that may have been caused by solar or magnetic field activities, we found ionospheric anomalies before the occurrence of five of the seven selected earthquakes. The number of repeated times at each grid point appearing at various time points during the anomalous period was used to analyze the

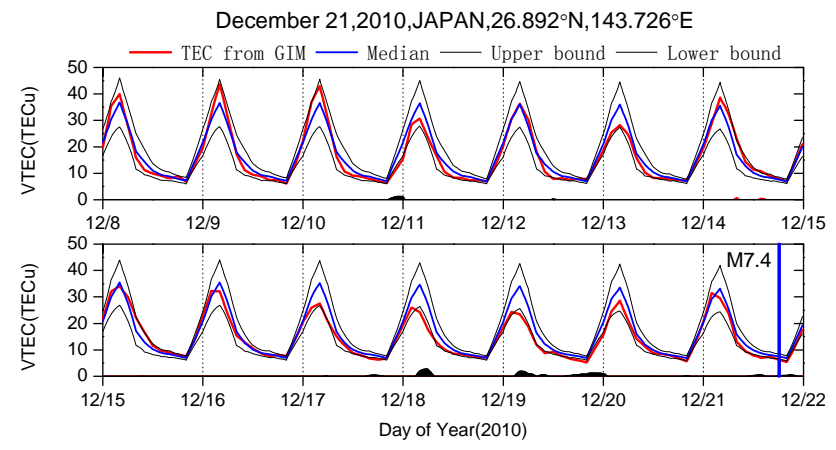

Fig. 19. VTEC time series above the Japan epicenter during 8 December 2010 to 21 December 2010. Symbols in this figure are the same as those in Fig. 3.

spatial distribution of the ionospheric anomalies and further confirm the relationship between the ionospheric anomalies and the earthquakes.

By analyzing the variations in the ionosphere before the occurrence of the seven earthquakes, we conclude that a preearthquake ionospheric anomaly is not bound to occur. No obvious ionospheric anomaly occurred before the 27 February $2010 M=8.8$ Chile earthquake and the 4 April 2010 $M=7.2$ Mexico earthquake. The ionospheric variations (relative to a normal non-perturbed state) may be positive or negative. Four earthquakes had positive anomalies, while the anomaly prior to the 21 December 2010 Japan earth- 

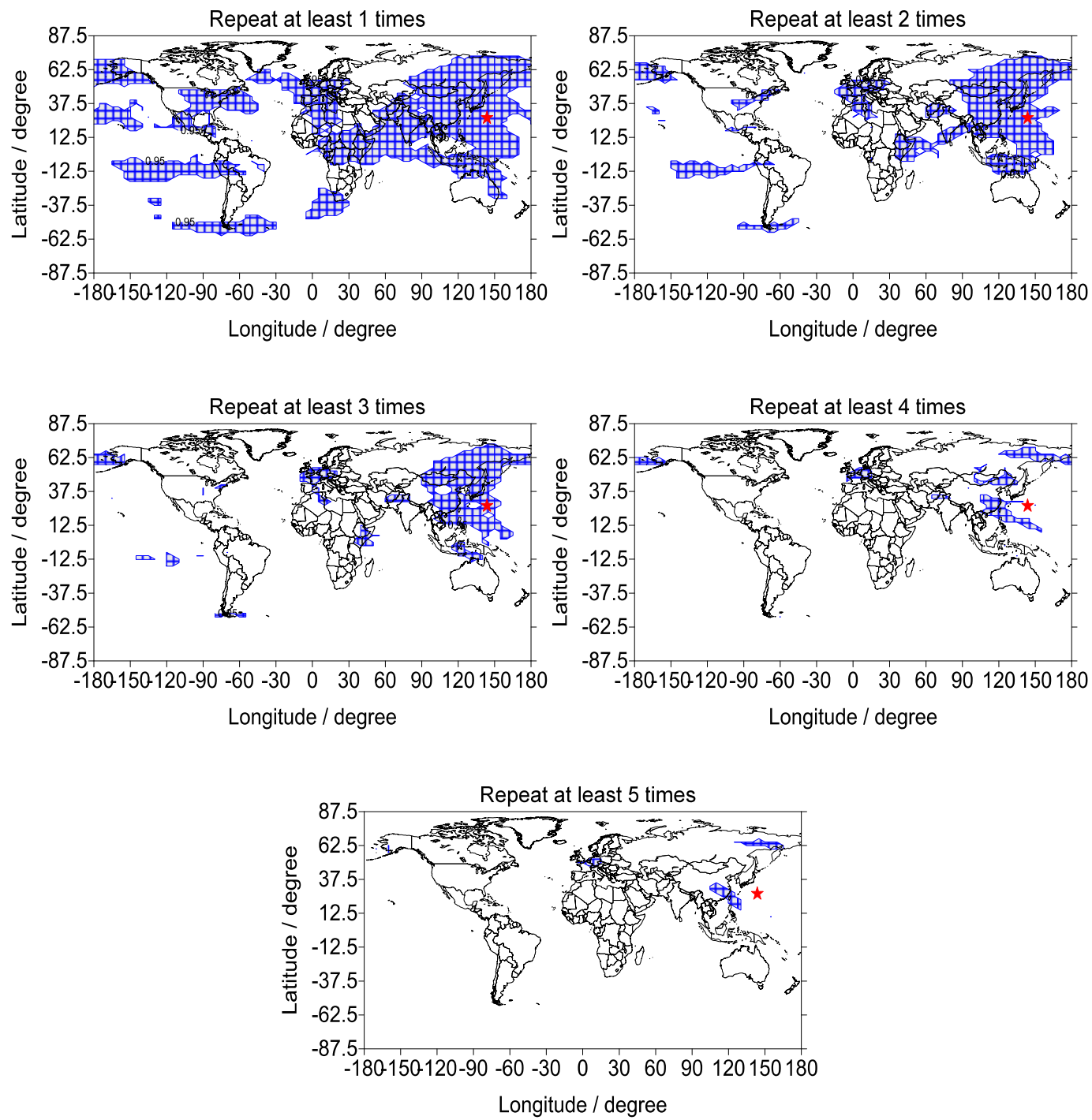

Fig. 20. Locations of the 30-day extreme enhancement that repeatedly appeared at various time points on 19 December 2010.

quake was negative. The ionospheric anomalies discussed in the current paper generally occurred in the afternoon and/or evening (12:00 LT-20:00 LT) 0-2 days before the earthquake occurrence. The affected region in the ionosphere was mainly concentrated in the vicinity of the epicenter. However, the anomaly peak did not coincide with the vertical projection of the epicenter, and no fixed rule for the direction of deviation from the epicenter was observed. Four anomalies were located on the equatorial side of the epicenter, whereas the anomalous area of the 12 January 2010 Haiti earthquake was in the opposite direction, which is inconsistent with previous result of "the most affected area in the ionosphere were located on the equator side of the epicenter". Corresponding ionospheric effects were also observed in the magnetically conjugated region, but both the probability and amplitude are lower than those near the epicenter region.
An ionospheric anomaly also occurred 8-11 days before the 4 April 2010 Mexico earthquake. The geomagnetic field was very quiet during those three days, and no earthquake occurred within six days after the anomaly. Therefore, the anomaly may have been caused by other reasons. He et al. (2011) and Le et al. (2011) statistically studied pre-earthquake ionospheric anomalies using different methods. They found that anomalies occurring before deep focus earthquakes had smaller intensity and occurrence rates. The 12 August $2010 M=7.1$ Ecuador earthquake, however, which had a deep hypocenter depth of $211 \mathrm{~km}$, also exhibited obvious pre-earthquake ionospheric anomalies, indicating that deep focus earthquakes can also trigger ionospheric anomalies. This result is not entirely consistent with He's and Le's results. Therefore, whether the pre-earthquake ionospheric anomalies are related to the focal depth still needs further study. 
Acknowledgements. The authors would like to thank the IGS for providing GNSS observations and global ionosphere map data; the NASA and IUGG for providing solar and geomagnetic field data; and the USGS for providing earthquake information. This research was accomplished at the Key Laboratory of Geospace Environment and Geodesy, Wuhan University, Ministry of Education, and was supported by the National Natural Science Foundation of China (41021061; 41174012) and the Surveying and Mapping Foundation Research Fund Program, State Bureau of Surveying and Mapping (10-02-13).

Edited by: M. E. Contadakis

Reviewed by: two anonymous referees

\section{References}

Astafyeva, E. and Heki, K.: Vertical TEC over seismically active region during low solar activity, J. Atmos. Sol.-Terr. Phys., 73, 1643-1652, 2011.

Calais, E. and Minster, J. B.: GPS detection of ionospheric perturbations following the January 17, 1994, Northridge Earthquake, Geophys. Res. Lett., 22, 1045-1048, 1995.

Chavez, O., Pérez-Enríquez, R., Cruz-Abeyro, J. A., MillanAlmaraz, J. R., Kotsarenko, A., and Rojas, E.: Detection of electromagnetic anomalies of three earthquakes in Mexico with an improved statistical method, Nat. Hazards Earth Syst. Sci., 11, 2021-2027, doi:10.5194/nhess-11-2021-2011, 2011.

Dautermann, T., Calais, E., Haase, J., and Garrison, J.: Investigation of ionospheric electron content variations before earthquakes in southern California, 2003-2004, J. Geophys. Res., 112, B02106, doi:10.1029/2006jb004447, 2007.

Hasbi, A. M., Mohd Ali, M. A., and Misran, N.: Ionospheric variations before some large earthquakes over Sumatra, Nat. Hazards Earth Syst. Sci., 11, 597-611, doi:10.5194/nhess-11-597-2011, 2011.

He, Y., Yang, D., Qian, J., and Parrot, M.: Response of the ionospheric electron density to different types of seismic events, Nat. Hazards Earth Syst. Sci., 11, 2173-2180, doi:10.5194/nhess-112173-2011, 2011.

Kim, V. P. and Hegai, V. V.: A possible presage of strong earthquakes in the night-time mid-latitude region ionosphere, atmospheric and ionospheric electromagnetic phenomena associated with earthquake, Tokyo: Terra Scientific Publishing Company, 619-627, 1999
Le, H., Liu, J. Y., and Liu, L.: A statistical analysis of ionospheric anomalies before 736 M6.0+ earthquakes during 2002-2010, J. Geophys. Res., 116, A02303, doi:10.1029/2010ja015781, 2011.

Liu, J. Y., Tsai, Y. B., Chen, S. W., Lee, C. P., Chen, Y. C., Yen, H. Y., Chang, W. Y., and Liu, C.: Giant ionospheric disturbances excited by the $M 9.3$ Sumatra earthquake of 26 December 2004, Geophys. Res. Lett., 33, L02103, doi:10.1029/2005g1023963, 2006.

Liu, J. Y., Chen, Y. I., Chen, C. H., Liu, C. Y., Chen, C. Y., Nishihashi, M., Li, J. Z., Xia, Y. Q., Oyama, K. I., Hattori, K., and Lin, C. H.: Seismoionospheric GPS total electron content anomalies observed before the 12 May $2008 M_{w} 7.9$ Wenchuan earthquake, J. Geophys. Res., 114, A04320, doi:10.1029/2008ja013698, 2009.

Liu, J. Y., Le, H., Chen, Y. I., Chen, C. H., Liu, L., Wan, W., Su, Y. Z., Sun, Y. Y., Lin, C. H., and Chen, M. Q.: Observations and simulations of seismoionospheric GPS total electron content anomalies before the 12 January 2010 M7 Haiti earthquake, J. Geophys. Res., 116, A04302, doi:10.1029/2010ja015704, 2011.

Oyama, K.-I., Kakinami, Y., Liu, J.-Y., Kamogawa, M., and Kodama, T.: Reduction of electron temperature in low latitude ionosphere at $600 \mathrm{~km}$ before and after large earthquakes, J. Geophys. Res., 113, A11317, doi:10.1029/2008ja013367, 2008.

Pulinets, S. A.: Natural radioactivity, earthquakes, and the ionosphere, Eos Trans. AGU, 88, 217-224, 2007.

Pulinets, S. A. and Boyarchuk, K..: Ionospheric precursors of earthquakes, Berlin: Springer, 2004.

Pulinets, S. A., Legen'ka, A. D., Gaivoronskaya, T. V., and Depuev, $\mathrm{V}$. Kh: Main phenomenological features of ionospheric precursors of strong earthquakes, J. Atmos. Sol. Terr. Phys., 65, 1337 1347, 2003.

Sharma, K., Dabas, R. S., Sarkar, S. K., Das, R. M., Ravindran, S., and Gwal, K.: Anomalous enhancement of ionospheric $F_{2}$ layer critical frequency and total electron content over low latitudes before three recent major earthquakes in China, J. Geophys. Res., 115, A11313, doi:10.1029/2009ja014842, 2010.

Yao, Y. B., Chen, P., Wu, H., Zhang, S., and Peng, W. F.: Analysis of ionospheric anomalies before the $2011 M_{\mathrm{W}}=9.0$ Japan earthquake, Chin. Sci. Bull., 57, 500-510, doi:10.1007/s11434011-4851-y, 2012.

Zhao, B., Wang, M., Yu, T., Wan, W., Lei, J., Liu, L., and Ning, B.: Is an unusual large enhancement of ionospheric electron density linked with the 2008 great Wenchuan earthquake?, J. Geophys. Res., 113, A11304, doi:10.1029/2008ja013613, 2008. 